\title{
A Study of Metal Free Supercapacitors Using 3D Printing
}

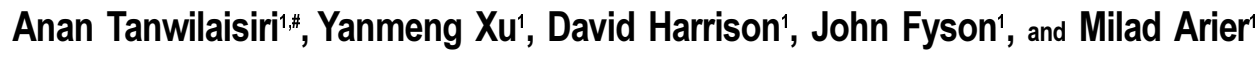 \\ 1 College of Engineering, Design and Physical Sciences Brunel University Kingston Lane Uxbridge Middlesex London, UB83PH, United Kingdom \\ \# Corresponding Author / E-mail: anan.tanwilaisiri@brunel.ac.uk, TEL: +44-1-895-265883 \\ ORCID: 0000-0002-8156-817X
}

KEYWORDS: 3D printing, Metal free supercapacitors, Carbon conductive paint, Electrode thickness, Energy storage device

\begin{abstract}
Metal-free supercapacitors were designed and fabricated using a 3D printing process. An attempt was made to use carbon conductive paint to create both current collector and electrode. Two 3D printing techniques were combined and used to manufacture the electric double layer capacitors (EDLCS). The electrode material made from carbon conductive paint and distilled water showed a good electrical performance. The manufacturing process for the EDLCs has been explained in detail and the process showed a good reproducibility. Different thicknesses of electrode were tested and characterized. The results showed that both the mass of the electrode material and the capacitance of the supercapacitor increased as the thickness of the active layer increased. The thickness of the electrode increased 4 times from $0.5 \mathrm{~mm}$ to $2.0 \mathrm{~mm}$, the mass of the electrode material increased nearly 3 times from $0.514 \mathrm{~g}$ to 1.498 $g$, which resulted in the increase of capacitance from $0.133 \mathrm{~F}$ to $0.295 \mathrm{~F}$.
\end{abstract}

\section{Introduction}

Supercapacitors or electric double layer capacitors (EDLCs) typically consist of two electrodes (an anode and a cathode) insulated from electrical contact by a dielectric layer. Both electrodes and separator are immersed in electrolyte solution which allows ion transport across the interface of electrode/electrolyte. ${ }^{1-5}$ Usually, both electrodes are formed on a metallic current-collector such as aluminium foil and copper foil for the anode and the cathode, respectively, and are covered with active materials which offer a high specific surface area to store the electrical charge.,7 During the charge and discharge processes in a supercapacitor, current collectors allow the flow of charge carriers (electrons) through an external circuit between the active materials. Therefore, an effective surface contact between the current collectors and the electrodes is necessary in order to decrease the contact resistance, otherwise, a high interfacial resistance can result from oxidation which arises from unstable electrochemical materials in both the current collectors and electrodes. ${ }^{8,9}$

Many researchers have reported different methods of improving the performance of current collectors in supercapacitors. ${ }^{10,11}$ Portet et al., ${ }^{10}$ have introduced a sol-gel deposit of a conducting carbonaceous material for modification of an aluminium current collector surface. In this method, the film consisting of carbonaceous material powder in a polymeric sol was coated onto aluminium foil to use as a current collector in a supercapacitor system. Another study by Bo et al. ${ }^{11}$ presented vertically oriented graphene (VG) nanosheets covering a surface of nickel foam using the plasma-enhanced chemical vapour deposition (PECVD) process. In this study, the VG nanosheets were applied as a bridge to improve the connection between current collectors and active electrode material. There are also several studies of metal-free supercapacitors which attempt to prevent corrosion problems of current collectors. ${ }^{12-16}$ In most of these works, current collectors were fabricated using graphite foil or carbon nanotubes using coating method on different thin films. Zhou et al. ${ }^{12}$ employed superaligned carbon nanotubes as a nanoporous current collector. Superaligned carbon nanotubes were produced that combine the advantages of carbon nanotubes and metal oxide nanoparticles and were made into a thin film applied to the current collector. Dyatkin et al. ${ }^{13}$ reported a green supercapacitor using environmentally friendly materials. In this study, three different carbon materials (carbon nanotubes, carbon fibre mat and graphite-foil sheets) were examined and the results showed that graphite-foil sheets have sufficient conductivity and are suitable for use as current collectors. Thin film supercapacitors in work by Liu et al. ${ }^{14}$ were created by combining all-carbon thin films with plastic paper and gel electrolyte. Current collectors in these supercapacitors were made from highly-conductive double-wall carbon nanotubes, (DWCNT) coated onto plastic papers. Also Xu et al. ${ }^{15}$ reported a supercapacitor with a high capacitance using a metal-free electrode 
material. In this research, polyaniline (PANI) and graphene composite monolith were constructed which showed a record high volumetric capacitance of over $800 \mathrm{~F} \mathrm{~cm}^{-3}$. Moreover, there is another research in metal-free supercapacitors using an aqueous electrolyte and low-cost carbon materials introduced by Blomquist et al.. ${ }^{16}$ The supercapacitors in this research were created with the purpose of being environmentally friendly and cost-effective. The materials used were a mixture of nanographite, activated carbon (AC) and nanofibrillated cellulose (NFC) for building the electrodes, and graphite foils were used as current collectors.

As mentioned above, coating methods on different thin films have been employed to develop current collectors of supercapacitor and also to create metal-free supercapacitors but these have not included 3D printing techniques which offer the possibility of creating objects with different materials for a wide range of applications including integration of electronic components into objects. ${ }^{17-21}$ This research has developed the use of $3 \mathrm{D}$ printing techniques to fabricate metal-free supercapacitors using a combination of two different 3D printing technologies (FDM and a paste extrusion system). The metal-free supercapacitors in this study were manufactured in two stages, 1) the FDM 3D printer was used to print the frame of the supercapacitors, and 2) the current collector layer, the electrode layer and the separator with the electrolyte layer were deposited using the paste extrusion system. In addition, instead of using metallic material for building current collectors carbon conductive paint was adopted for both current collectors and electrodes. The method described in this paper shows a new approach for manufacturing metal-free supercapacitors. The effectiveness of different thickness of electrodes has been assessed and the reproducibility of the manufacturing process for the supercapacitors has been investigated in this work.

\section{Experimental}

\subsection{Material}

The frames of supercapacitors were built using polylactic acid (PLA) filaments with a diameter of $2.89 \mathrm{~mm}$. The current collectors and electrodes in this experiment were made from carbon conductive paint (Bare Conductive Electric Paint). This carbon conductive paint offers the possibility of creating electrically conductive areas onto objects using $3 \mathrm{D}$ printing. The carbon conductive paint is a water-based material which is non-toxic and organic solvent free, and is used for making low-current circuits and sensors. The electrolyte in this study consists of phosphoric acid and PVA. The gel electrolyte was made by dissolving $0.8 \mathrm{~mL} \mathrm{H}_{3} \mathrm{PO}_{4}$ and $1.0 \mathrm{~g}$ PVA in $10 \mathrm{~mL}$ deionized water.

\subsection{Fabrication method}

An FDM printer was combined with a paste extrusion system, so that the device could be printed in a single process. The FDM printer first prints a plastic casing for the device consisting of two halves joined by a hinge. Once complete, the paste extruder is used to first print silver paint current collectors on each half, and then to print carbon electrodes on top. Afterwards the paste extruder also prints the electrolyte separator. PVA electrolyte gel is used as the separator so the fabrication process is entirely $3 \mathrm{D}$ printed except for the closing of the

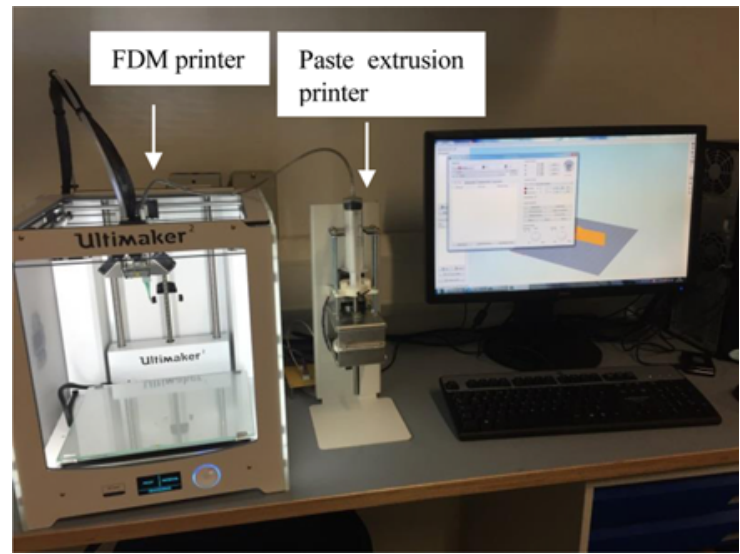

Fig. 1 The combination of two 3D printers for manufacturing the metal-free supercapacitors

casing (i.e., combining the two halves). The printing parameters of both printers were controlled via CURA software, which is open source software.

The development of FDM machines has provided a wide range of potential fabrication materials allowing the creation of parts with various effective mechanical properties. Parts created using FDM technology are the strongest in comparison with any other polymerbased 3D printing processes. Desktop FDM printers mainly use either acrylonitrile butadiene styrene (ABS) or polylactic acid (PLA) as building materials. Both materials have subordinate thermostability, when $\mathrm{ABS}$ is heated above $250^{\circ} \mathrm{C}$, it can decompose into acrylonitrilemonomer, butadiene-monomer, and styrene-monomer. These monomers are highly toxic. In contrast, the PLA is much safer in this respect, as it decomposes into $\mathrm{H}_{2} \mathrm{O}, \mathrm{CO}_{2}$ and humus. Moreover, PLA is "greener", because it produced from renewable resources such as cassava and corn, and is biodegradable. Unlike ABS, the PLA filament also offers low-cost, low-melting point (around $160^{\circ} \mathrm{C}$ ) and good mechanical properties. As a result of these advantages, the PLA filament is increasingly used for FDM printing by industrial and general users. ${ }^{22-24}$

As shown in Fig. 2, the FDM printer works by feeding the thermoplastic filament material off a feedstock spool using two rollers. The filament is heated and transformed into a semi-molten polymer via a small temperature-controlled extruder which then deposits it onto the build platform on a layer by layer basis. To fabricate the object, the heated extruder moves on an $\mathrm{x}-\mathrm{y}$ plane to deposit the semi-molten filament according to the layer design. After each layer is complete, the build platform is lowered and the next layer is deposited, and so on until object is entirely built. The build platform is also able to control the temperature to facilitate the rapid hardening of thermoplastic filament. ${ }^{25,26}$

The paste extrusion process (also referred to as direct-write technology) applies pressure to deposit paste or fluid materials thorough a nozzle to control the composition onto the substrate. ${ }^{22}$ This process varies from FDM in requiring no heating of the material before deposition. The main advantages of this process are the ability to deposit several paste materials on to different substrate surfaces and a simpler fabrication method. ${ }^{27-30}$ Due to these advantages and 


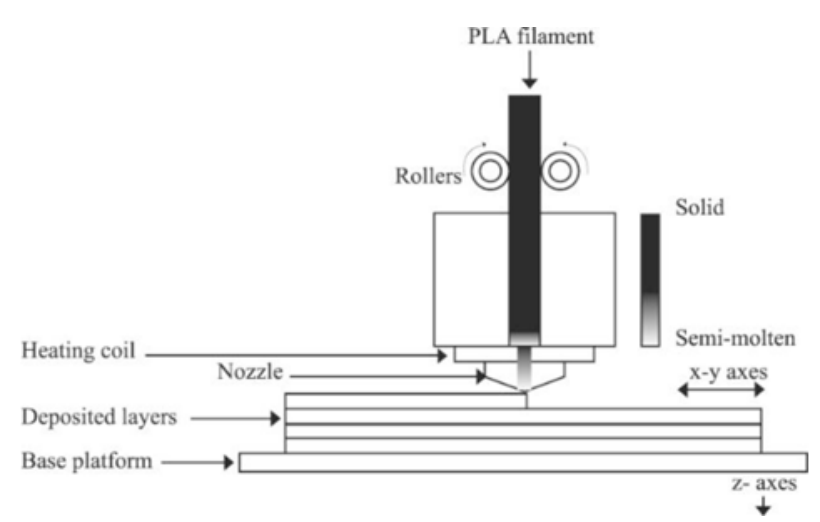

Fig. 2 Schematic diagram of the extrusion and deposition of FDM process

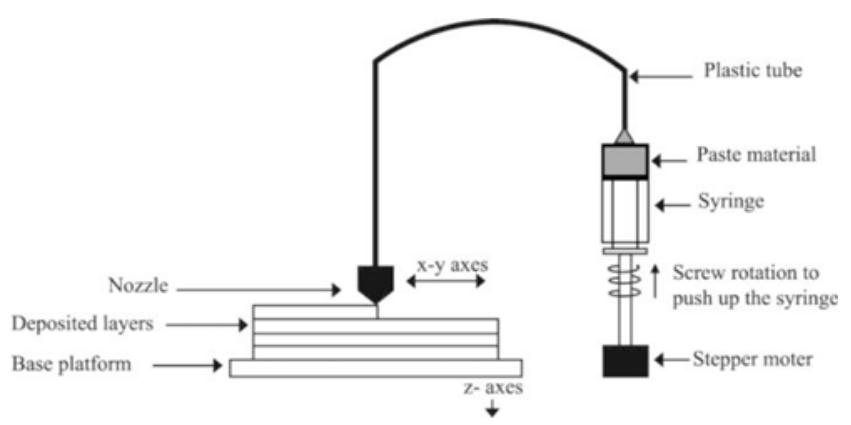

Fig. 3 Schematic diagram of the extrusion of paste extrusion system

improvements in material deposition technology, it is possible to print electronic components onto or within complex three-dimensional objects. $^{29,30}$

As shown in Fig. 3, the paste extrusion system consists of a stepper motor, a syringe connected to a plastic tube and a nozzle at the end of plastic tube. To extrude the paste material, the stepper motor is driven to rotate the screw underneath the syringe plunger. After the plunger is pushed, the paste material flows through the plastic tube into the nozzle, and the material is then deposited in the desired position.

\subsection{Design the structure of metal-free supercapacitor}

Fig. 4 shows the schematic diagram of the extendable metal-free supercapacitor designed for this study. The supercapacitor consists of two current collectors and two electrodes divided by a separator containing the electrolyte in the middle. There is a hinge in the middle of the frame, and linking parts at the bottom of the frame. The main advantages of this design are 1) the frame can be closed up easily after all layers were printed in order to form a complete energy storage module without further assembly, 2) the modular energy storage can be extended by connecting more together to provide desired electric power.

\subsection{Preparation of the activated carbon (AC) slurry for current collectors and electrodes}

Table 1 shows different types of the AC slurry made from carbon conductive paint mixed with distilled water. Five different AC slurries were prepared for the use as current collector and electrode. The carbon

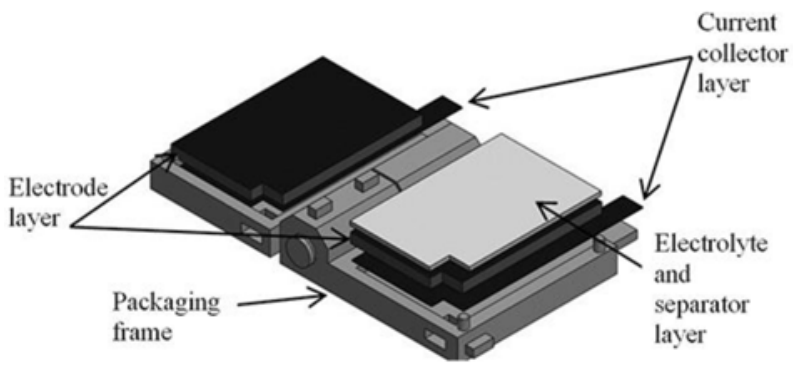

Fig. 4 Schematic of the structure of metal-free supercapacitor

Table 1 List of AC different types of AC slurry

\begin{tabular}{cccc}
\hline $\begin{array}{c}\text { AC } \\
\text { slurry }\end{array}$ & $\begin{array}{c}\text { Carbon Conductive } \\
\text { paint }(\mathrm{g})\end{array}$ & $\begin{array}{c}\text { Distilled } \\
\text { Water }(\mathrm{g})\end{array}$ & $\begin{array}{c}\text { Concentration } \\
\text { of the paint }(\mathrm{wt} \%)\end{array}$ \\
\hline no: 1 & 1.0 & 20 & 4.76 \\
no: 2 & 1.5 & 20 & 6.97 \\
no: 3 & 2.0 & 20 & 9.09 \\
no: 4 & 2.5 & 20 & 11.11 \\
no: 5 & 3.0 & 20 & 13.04 \\
\hline
\end{tabular}

conductive paint is solvent free and water soluble which can be used in stencil and screen printing processes. In this study, the distilled water was fixed at $20 \mathrm{ml}$ and mixed with carbon conductive paint of $1,1.5$, $2.0,2.5$, and $3.0 \mathrm{~g}$ individually. The slurry was stirred for 2 hours to make a homogenous mixture. This slurry does not separate during the processing. When making the AC slurry for depositing using 3D printing, the suitable slurry should not be too viscous in order to flow along the tube of the deposition system. The slurry made with $3.0 \mathrm{~g}$ of the carbon conductive paint was tested and found to be too viscous so that the mixture of slurry could not be deposited through the nozzle of the printing head. It is noted that as the concentration of carbon in the carbon conductive paint is unknown, so the concentration of the paint was used to represent the amount of carbon in the slurry, which was the weight of carbon conductive paint divided by the total weight of the mixture between the paint and distilled water.

\subsection{Fabrication of metal-free supercapacitor}

The frame of the supercapacitor was designed by Solidworks and created using the FDM printing machine. PLA filament was melted in the heated nozzle of the FDM printer and extruded to draw the part's cross-sectional geometry layer by layer. The speed of printing was adjusted to $50 \mathrm{~mm} / \mathrm{sec}$. The fill density was set at $20 \%$ and the wall line width at $0.6 \mathrm{~mm}$. The temperature of the FDM printing nozzle was heated to $220^{\circ} \mathrm{C}$ and the bed of the printer was controlled at $60^{\circ} \mathrm{C}$. All the printing parameters of the FDM printer were adjusted properly in order to control the stability of the frame manufacturing process. The FDM printer was automatically controlled using an open source software (CURA), which was used to convert all printing parameters to STL file format.

The paste extrusion system was used to print the current collectors, the electrodes and the separator with electrolyte. The paste extrusion system enabled a simple fabrication method for paste materials. Carbon conductive paint was prepared as above and was deposited to build both current collectors and electrodes. The slurry was deposited to 


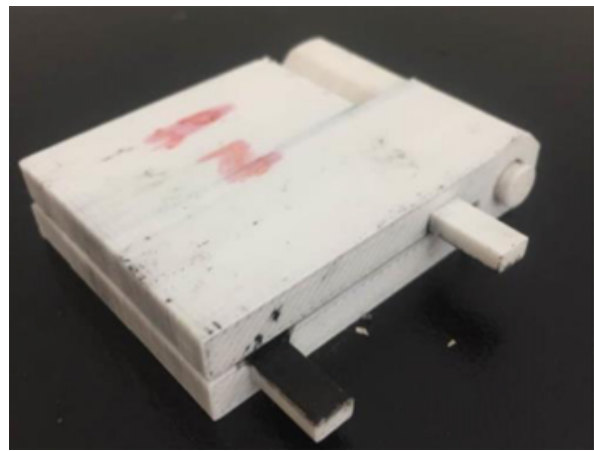

Fig. 5 A complete 3D printed metal free supercapacitor

match the thickness of the frame of the supercapacitors. After the current collectors and electrodes were printed and dried at room temperature (approximately $22-24^{\circ} \mathrm{c}$ ), the separator of PVA gel electrolyte was printed on top of the electrodes. Then the two sides of the frame were simply folded over to form an assembled electrochemical supercapacitor as shown in Fig. 5.

\subsection{Electrochemical measurement}

When an electric potential is applied between the two electrodes in an EDLC, opposite ion charges accumulate on the surfaces of the electrodes. The two electrodes in an EDLC are separated by a separator in order to avoid short-circuit and therefore an electric field is created between the two electrodes to form a means of storing electrical energy. In this study, the electrochemical performance of the printed supercapacitor was studied by cyclic voltammetry (CV) and galvanostatic charge/discharge using a Versa-STAT3 electrochemical workstation. The Versa-STAT3 was set up in two electrode mode as a potentiostat or a galvanostat as required. Cyclic voltammetry (CV) is an effective method in the area of electrochemistry. It has been applied to characterize the performance of several electrical energy storage devices, for example batteries and supercapacitors. Galvanostatics charge/discharge (GCD) is an alternative method used to evaluate the performance of the supercapacitors under controlled current conditions. This method is the most preferred DC (direct current) test and is not only used in the laboratory but also in industry.

\subsubsection{Cyclic voltammetry}

The CV test applied a linear potential sweep to the working electrode. A positive (charging) voltage sweep with a set $\mathrm{dV} / \mathrm{dt}$ (scan rate) over a specific voltage range is applied and then reversing (discharging) voltage sweep immediately after the maximum voltage is reached. Measurement of electrochemical behaviour of the supercapacitor can be calculated from the current response against the applied voltage. The capacitance, C, of the EDLC can be calculated by the following Eq. (1): $:^{4,5}$

$$
C_{1}=\frac{Q_{\text {total }}}{2 \Delta V}
$$

Where $Q_{\text {total }}$ is the supercapacitor's charge in coulombs. This value is measured from the $\mathrm{CV}$ response curve. $\Delta V$ is the voltage change between the device's terminals in volts $(\mathrm{V})$.

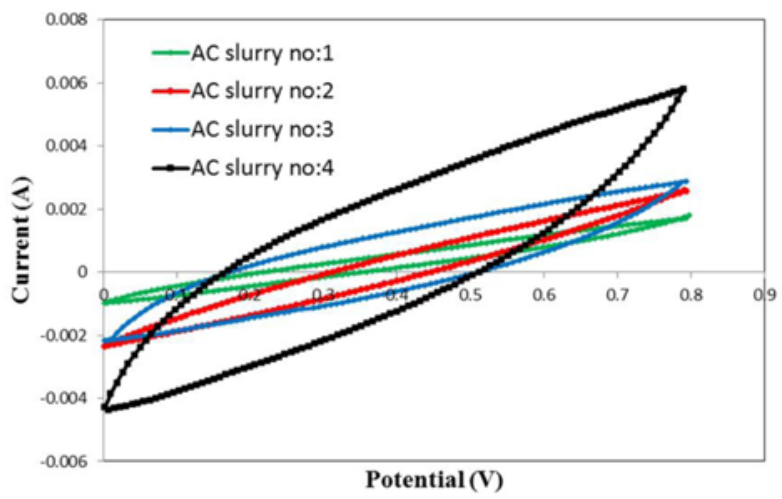

(a) The cyclic voltammogram curves of the four EDLC samples with different concentrations of AS slurries

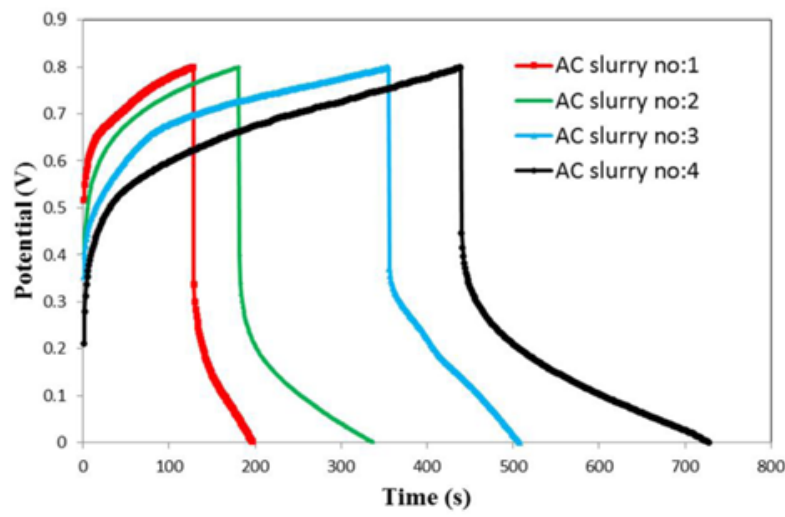

(b) Galvanostatic charge/discharge curves of the four EDLC samples with different concentrations of AC slurries

Fig. $6 \mathrm{CV}$ and GCD measurements for the four EDLC samples with different concentrations of $\mathrm{AC}$ slurries

The specific capacitance can be calculated as the Eq. (2): $:^{3,7}$

$$
C s_{1}=\frac{C}{m}
$$

Where, $\mathrm{Cs}_{1}$ is the specific capacitance of the electrodes, $\mathrm{C}$ is the capacitance calculated from Eq. (1), $m$ is the weight of active materials of each electrodes $(\mathrm{g})$.

\subsubsection{Galvanostatic charge/discharge}

Galvanostatic charge/discharge (GCD) tests can be used to evaluate the performance of the supercapacitors, and is the most preferred DC (direct current) test. The measurement is completed in two steps: 1) a constant current is charging a supercapacitor then 2) discharging in a specific voltage range or charge/discharge time. The capacitance $\mathrm{C}$ can be calculated by the following equation: ${ }^{3-5}$

$$
C_{2}=\frac{i \times \Delta t}{\Delta v}
$$

Where, $i$ is the discharge current in amperes (A), $\Delta t$ is the discharging time (s) and $\Delta v$ is the voltage of the discharge excluding $\mathrm{iR}$ drop (V).

In addition, specific capacitance $\left(\mathrm{Cs}_{2}\right)$ can be calculated by the following equation: ${ }^{3-5}$ 


$$
C s_{2}=\frac{i \times \Delta t}{m \times \Delta v}
$$

Where, $i$ is current in amperes (A), $\Delta t$ is the discharging time (s), $\mathrm{m}$ is the total weight of active materials of two electrodes $(\mathrm{g})$ and $\Delta v$ is the voltage of the discharge $(\mathrm{V})$.

\section{Results and Discussions}

\subsection{The effect of the concentration of carbon conductive paint}

To define the suitable concentration of AC slurries, carbon conductive paint was prepared in five different concentrations as shown in Table 1. Four different AC slurries (no: 1-4) were selected as the material to build current collectors and electrodes as they had proper viscosities that enabled deposition by the paste extrusion system. AC slurry no: 5 was too sticky and could not be deposited. Four metal-free supercapacitors were fabricated with a laydown thickness of $0.5 \mathrm{~mm}$ using AC slurries containing different concentrations of carbon conductive paint. The $\mathrm{CV}$ curves were recorded using a potential window range of $0.8 \mathrm{~V}$ at the scan rate of $0.02 \mathrm{~V} / \mathrm{s}$, and the GCD curves were recorded at a charge current of $15 \mathrm{~mA}$, as shown in Figs. 6(a) and 6(b).

Table 2 shows the capacitance of $\mathrm{C} 1$ and $\mathrm{C} 2$ of the four samples calculated from the $\mathrm{CV}$ and $\mathrm{GCD}$ measurements and their corresponding specific capacitance Cs1 and Cs2. The shape of the CV curve shown in Fig. 6(a) demonstrates that the device worked as a typical supercapacitor, which implied that the carbon conductive paint can be used as an appropriate material for both current collector and electrode. The maximum capacitance achieved was $0.133 \mathrm{~F}$ at the scan rate of $0.02 \mathrm{~V} / \mathrm{s}$. As the results shown in Table 3, the metal-free supercapacitor made from AC slurry no:4 (carbon conductive paint 2.5 g mixed with $20 \mathrm{ml}$ distilled water) produced a higher capacitance compared to the other AC slurries under the same manufacturing and testing conditions. Fig. 7 shows the relationship between the concentration of carbon conductive paint and the capacitance of metalfree supercapacitor. It can be seen that the capacitances of the samples increased with increasing concentration of carbon conductive paint in the AC slurries. The concentration of AC in the slurries in this experiment increased by adding more carbon conductive paint into distilled water, which suggests an increase amount of carbon in the slurries. When the amount of activated carbon was increased, the conductivity of AC slurries increased and the capacitance of the metalfree supercapacitor increased consequently. However, increasing the amount of carbon conductive paint further for making AC slurry has to be a concern because the excessive viscosity of the AC slurry will not be suitable for $3 \mathrm{D}$ printing.

In addition, the capacitance in this experiment can be affected by the different printing times required to build the electrode in order to complete the $0.5 \mathrm{~mm}$ thickness. Due to different concentrations of these slurries, less concentrated AC slurries had to be deposited around five times to achieve the thickness of $0.5 \mathrm{~mm}$. On the other hand, the high concentration AC slurry was deposited twice to achieve at the same thickness as shown in Table 3. Although the thicknesses of these EDLC samples were similar, they were created with different layers. More
Table 2 Capacitance and specific capacitance of the four samples calculated from CV curve and GCD curves

\begin{tabular}{cccccc}
\hline \multirow{2}{*}{$\begin{array}{c}\text { AC } \\
\text { slurry }\end{array}$} & $\begin{array}{c}\text { Concentration of } \\
\text { the paint }(w t \%)\end{array}$ & \multicolumn{2}{c}{$\begin{array}{c}\text { Calculated from } \\
\text { CV curve }\end{array}$} & \multicolumn{2}{c}{$\begin{array}{c}\text { Calculated from } \\
\text { GCD curve }\end{array}$} \\
\cline { 3 - 6 } & & C1 (F) & Cs1 (F/g) & C2 (F) & Cs2 (F/g) \\
\hline no: 1 & 4.76 & 0.034 & 0.069 & 0.076 & 0.151 \\
no: 2 & 6.97 & 0.061 & 0.120 & 0.103 & 0.201 \\
no: 3 & 9.09 & 0.091 & 0.182 & 0.132 & 0.264 \\
no: 4 & 11.11 & 0.133 & 0.259 & 0.174 & 0.339 \\
\hline
\end{tabular}

Table 3 Deposition time and mass of electrode of different concentrations of the AC slurries

\begin{tabular}{cccc}
\hline $\begin{array}{c}\text { AC } \\
\text { Slurry }\end{array}$ & $\begin{array}{c}\text { Number of } \\
\text { deposit }\end{array}$ & $\begin{array}{c}\text { Mass of each } \\
\text { electrode layer }(\mathrm{g})\end{array}$ & $\begin{array}{c}\text { Mass of } \\
\text { Electrode }(\mathrm{g})\end{array}$ \\
\hline No: 1 & 5 & 0.101 & 0.511 \\
No: 2 & 4 & 0.127 & 0.516 \\
No: 3 & 3 & 0.173 & 0.513 \\
No: 4 & 2 & 0.259 & 0.515 \\
\hline
\end{tabular}

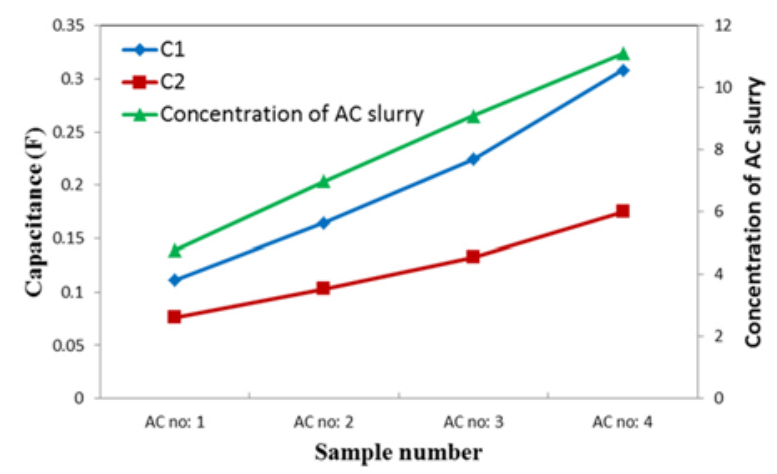

Fig. 7 The capacitances of the four EDLC samples with different concentrations of the AC slurries

printed layers will have generated more bonding layers compared to less printed layers of the same thickness, and this is considered to be a possible reason for a decrease in capacitance of these samples even though they had the same thickness and amount of material.

\subsection{Reproducibility of the manufacturing process}

After a suitable concentration of AC slurry for manufacturing metal-free supercapacitor was verified and tested, the reproducibility of the manufacturing process was investigated. Since the sample with AC slurry no: 4 has been approved to have the best performance, another three new metal-free EDLDCs were fabricated under the same conditions using the AC slurry no: 4 , and designated as sample A, B, and $C$. The thickness of electrode was set at $0.5 \mathrm{~mm}$. All the new EDLDs were characterized by CV and GCD tests. Figs. 8 (a) and 8(b) show the CV curve and GCD curve of the three new samples. The areas of the CV curves and GCD curves measured are almost the same. The average capacitance and specific capacitance calculated for the three new supercapacitors are about $0.131 \mathrm{~F}$, and $1.011 \mathrm{~F} / \mathrm{g}$ respectively, which is about $98 \%$ and $97 \%$ as the sample with AC slurry no: 4 described above. Standard deviations of all experimental data results are less than $0.01 \%$. Table 4 shows that the results of the capacitances and specific capacitances of all samples calculated from $\mathrm{CV}$ 


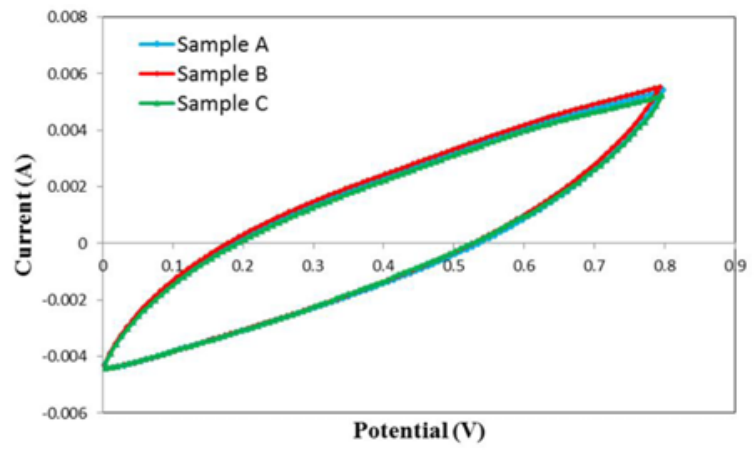

(a) The cyclic voltammogram curves of the three new EDLC samples at the scan rate of $0.02 \mathrm{~V} / \mathrm{s}$

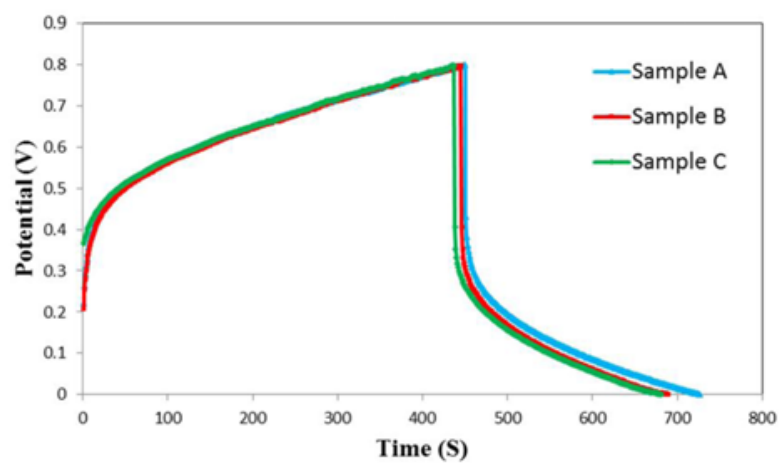

(b) Galvanostatic charge/discharge curves of the three EDLC samples at a charge current of $15 \mathrm{~mA}$

Fig. $8 \mathrm{CV}$ and GCD measurements for the three new EDLC samples with different $\mathrm{AC}$ slurries

Table 4 Capacitance and specific capacitance of the four samples calculated from $\mathrm{CV}$ curve and GCD curves

\begin{tabular}{ccccc}
\hline \multirow{2}{*}{ Sample } & \multicolumn{2}{c}{$\begin{array}{c}\text { Calculated from } \\
\text { CV curve }\end{array}$} & \multicolumn{2}{c}{$\begin{array}{c}\text { Calculated from } \\
\text { GCD curve }\end{array}$} \\
\cline { 2 - 5 } & C1 (F) & Cs1 (F/g) & C2 (F) & Cs2 (F/g) \\
\hline Sample A & 0.131 & 0.250 & 0.171 & 0.327 \\
Sample B & 0.131 & 0.255 & 0.171 & 0.334 \\
Sample C & 0.130 & 0.252 & 0.169 & 0.328 \\
Average value & 0.131 & 0.253 & 0.171 & 0.330 \\
Standard deviation (\%) & 0.0002 & 0.002 & 0.0008 & 0.002 \\
\hline
\end{tabular}

measurement using Eqs. (1) and (2) and from GCD measurement using Eqs. (3) and (4) are only slightly different. These results illustrates that the manufacturing process for the metal-free supercapacitors in this study has a very good reproducibility.

\subsection{The effect of the thickness of electrode on capacitance}

The metal-free supercapacitors were fabricated under the same conditions with different electrode thicknesses, which were $0.5 \mathrm{~mm}, 1.0$ $\mathrm{mm}, 1.5 \mathrm{~mm}, 2.0 \mathrm{~mm}$ and $2.5 \mathrm{~mm}$. The capacitances, $\mathrm{C} 1$ and $\mathrm{C} 2$, and their corresponding specific capacitances, Cs1 and Cs2, of the five samples were calculated from the $\mathrm{CV}$ and GCD measurements as shown in Table 5 and Figs. 9(a) and 9(b). Fig. 10 shows the mass of the two electrodes of the five metal-free EDLCs samples and their capacitances as a function of the electrodes thickness. The mass of electrode was measured before and after the AC slurry was deposited and dried. The

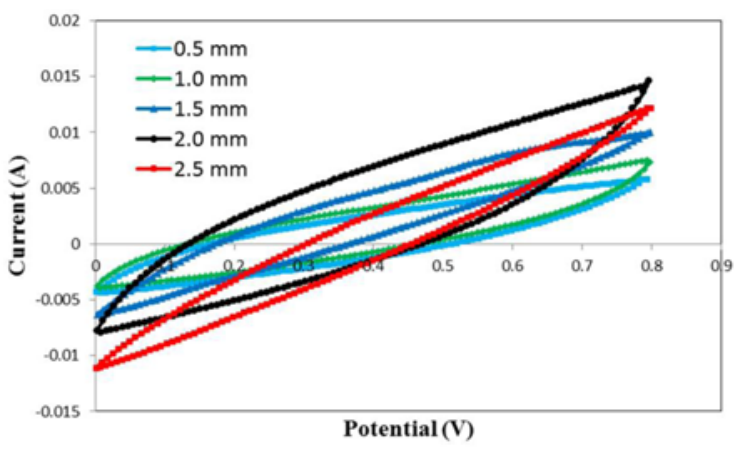

(a) The cyclic voltammogram curves of the five EDLC samples with different electrode thicknesses

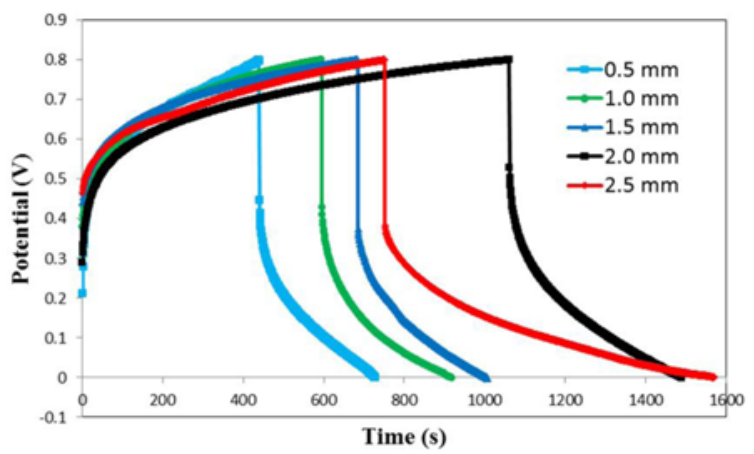

(b) Galvanostatic charge/discharge curves of the five EDLC samples with different electrode thicknesses

Fig. $9 \mathrm{CV}$ and GCD measurements for the five EDLC samples with different electrode thicknesses

Table 5 Capacitance and specific capacitance of the samples calculated from CV curve and GCD curves

\begin{tabular}{cccccc}
\hline $\begin{array}{c}\text { AC electrode } \\
\text { Thickness } \\
(\mathrm{mm})\end{array}$ & $\begin{array}{c}\text { Mass of } \\
\text { electrode }\end{array}$ & \multicolumn{2}{c}{$\begin{array}{c}\text { Calculated from } \\
\text { CV curve }\end{array}$} & \multicolumn{2}{c}{$\begin{array}{c}\text { Calculated from } \\
\text { GCD curve }\end{array}$} \\
\cline { 3 - 7 } & $(\mathrm{g})$ & $\mathrm{C} 1(\mathrm{~F})$ & Cs1 $(\mathrm{F} / \mathrm{g})$ & $\mathrm{C} 2(\mathrm{~F})$ & $\mathrm{Cs} 2(\mathrm{~F} / \mathrm{g})$ \\
\hline 0.5 & 0.514 & 0.133 & 0.259 & 0.173 & 0.338 \\
1 & 0.848 & 0.178 & 0.209 & 0.217 & 0.256 \\
1.5 & 1.174 & 0.228 & 0.194 & 0.269 & 0.229 \\
2 & 1.498 & 0.295 & 0.198 & 0.338 & 0.225 \\
2.5 & 1.828 & 0.250 & 0.136 & 0.290 & 0.159 \\
\hline
\end{tabular}

mass of electrode in this experiment also included the mass of current collector because of this slurry was used for both current collector and electrode, so it is believed that the current collector would function as part of the electrode attached with it. From this reason, when charging the supercapacitor samples, the current collector not only transported the electric charge to the electrode but also stored energy in the same time. The results shown in Fig. 10 clearly demonstrate that the AC electrode thickness directly affected the mass of $\mathrm{AC}$ electrode and also the capacitance of the samples. Below the thickness of $2 \mathrm{~mm}$, both capacitance and the mass of the electrodes increased linearly along with the increase of the thickness of the electrode. When the thickness of the electrode was increased above $2 \mathrm{~mm}$, i.e., $2.5 \mathrm{~mm}$, the capacitance of the EDLC sample decreased. The decrease of the capacitance obtained with the thicker electrode might be caused by the rate of electrolyte diffusion which will be extended when the thickness of electrode is 


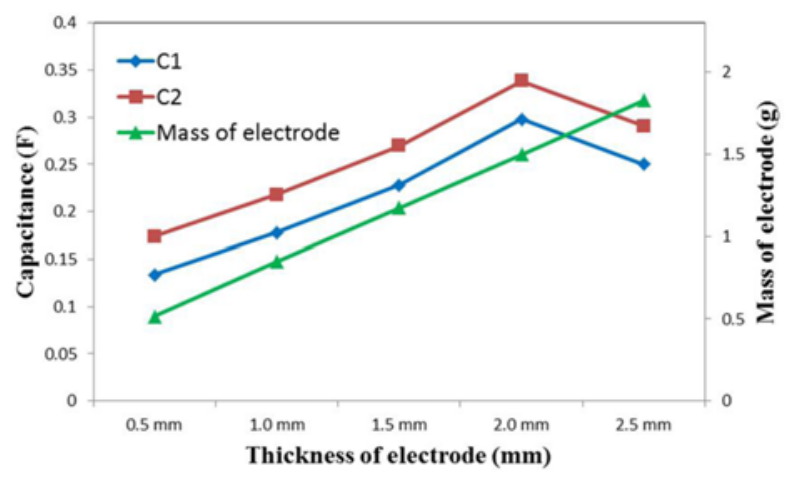

Fig. 10 Capacitances calculated from $\mathrm{CV}$ and $\mathrm{GCD}$ for the five samples with different electrode thicknesses

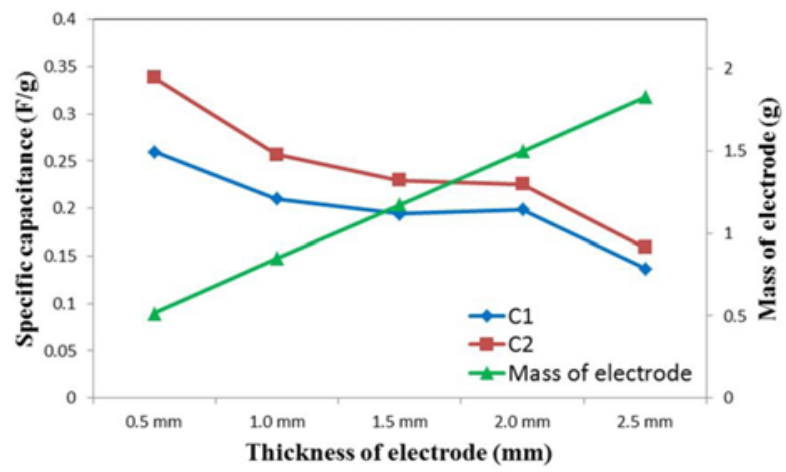

Fig. 11 Specific capacitances calculated from CV and GCD for the five samples with different electrode thicknesses

increased. In addition, the thicker electrode needed more printing times, which increased the internal resistance and thus resulted in a decrease of capacitance. Fig. 11 shows that the specific capacitances of the samples (Cs1 and Cs2) continuously decreased when the thickness of electrode increased. This is in good agreement with the literature review obtained by Wang, ${ }^{31}$ who suggested that the thin film electrode can produce a high specific capacitance because its low internal resistance and ease of electrolyte ion diffusion. On the other hand the specific capacitance of the electrode material could decrease when the electrode material was constructed of a thick layer because the transport of the electrolyte ions into/from active layers becomes more difficult. In addition, similar results of different electrode thickness have been reported previously. ${ }^{7,8}$

Table 6 shows a comparison of the metal-free supercapacitor based on a $3 \mathrm{D}$ printing process and the metal-free supercapacitors made using non $3 \mathrm{D}$ printing process. Compared to other methods for manufacturing metal-free supercapacitor, 3D printing techniques provided a possible way to create a supercapacitor frame in different sizes and shapes, and paste extrusion system allows the use of a wide range of materials that can be deposited through the system. The manner in which the FDM machine was combined with the paste extruder and modified so that samples could be printed in a single operation was an innovative approach. In addition to simplifying the process, it also allowed for more precision and less chance of human error, because the sample did not need to be moved from one machine to another.
Table 6 The metal-free supercapacitor with different manufacturing processes

\begin{tabular}{cccc}
\hline $\begin{array}{c}\text { Fabrication } \\
\text { process }\end{array}$ & Current collector/Electrode & $\begin{array}{c}\text { Specific } \\
\text { capacitance }\end{array}$ & Ref. \\
\hline $\begin{array}{c}\text { SACNT film } \\
\text { on glass }\end{array}$ & $\begin{array}{c}\text { CNTs and metal oxide } \\
\text { nanoparticles }\end{array}$ & $508 \mathrm{~F} / \mathrm{g}$ & {$[12]$} \\
$\begin{array}{c}\text { Blade coating } \\
\text { method }\end{array}$ & Graphite foil/Activated carbon & $82 \mathrm{~F} / \mathrm{g}$ & {$[13]$} \\
$\begin{array}{c}\text { Blade coating } \\
\text { method }\end{array}$ & DWCNT & $10 \mathrm{mFcm}^{-2}$ & {$[14]$} \\
$\begin{array}{c}\text { Dip coating } \\
\text { method }\end{array}$ & PANI/graphene composite & $800 \mathrm{Fcm}^{-3}$ & {$[15]$} \\
$\begin{array}{c}\text { Blade coating } \\
\text { method }\end{array}$ & Nanographite/Activated carbon & $55 \mathrm{~F} / \mathrm{g}$ & {$[16]$} \\
3D printing & Carbon conductive paint & $0.338 \mathrm{~F} / \mathrm{g}$ & $\begin{array}{c}\text { This } \\
\text { work }\end{array}$ \\
\hline
\end{tabular}

\section{Conclusions}

Metal-free supercapacitors using a combination of two 3D printing techniques were manufactured and characterized in this study. The current collector and electrode were made from carbon conductive paint. Different concentrations of carbon conductive paint provided different electrical performance and printability, i.e. the suitable AC slurry for $3 \mathrm{D}$ printing should not be too viscous in order to extrude easily in the system. The AC slurry made from $2.5 \mathrm{~g}$ carbon conductive paint and $20 \mathrm{ml}$ distilled water delivered a good electrical performance and could be easily deposited using a 3D printer. The manufacturing process described in this study showed a very good reproducibility. Different thicknesses of electrode directly affected the capacitance of EDLCs samples. The highest capacitance can be reached at $0.295 \mathrm{~F}$ with a thickness of $2.0 \mathrm{~mm}$ electrode; and the capacitance decreased with a further increase in thickness. However, the specific capacitance continuously decreased when the thickness of electrode increased. The thickness of the electrode increased from $0.5 \mathrm{~mm}$ to $2.0 \mathrm{~mm}$, the mass of the electrode material increased from $0.514 \mathrm{~g}$ to $1.498 \mathrm{~g}$, which further resulted in the increase of capacitance from $0.133 \mathrm{~F}$ to $0.295 \mathrm{~F}$. In addition, the specific capacitance of the samples continuously decreased when the thickness of electrode increased because the transport of the electrolyte ions into/from active layers becomes more difficult.

\section{ACKNOWLEDGEMENT}

This research did not receive any specific grant from funding agencies in the public, commercial, or not-for-profit sectors.

Open Access: The article published in this journal is distributed under the terms of the Creative Commons Attribution 4.0 International License (http://creativecommons.org/licenses/by/4.0/), which permits unrestricted use, distribution, and reproduction in any medium, provided you give appropriate credit to the original author(s) and the source, provide a link to the Creative Commons license, and indicate if changes were made. 


\section{REFERENCES}

1. Vangari, M., Pryor, T., and Jiang, L., "Supercapacitors: Review of Materials and Fabrication Methods," Journal of Energy Engineering, Vol. 139, No. 2, pp. 72-79, 2012.

2. Kötz, R. and Carlen, M., "Principles and Applications of Electrochemical Capacitors," Electrochimica Acta, Vol. 45, Nos. 1516, pp. 2483-2498, 2000.

3. Kim, B. K., Sy, S., Yu, A., and Zhang, J., "Electrochemical Supercapacitors for Energy Storage and Conversion," Handbook of Clean Energy Systems, 2015.

4. Zhang, R.-R., Xu, Y.-M., Harrison, D., Fyson, J., Qiu, F.-L., and Southee, D., "Flexible Strip Supercapacitors for Future Energy Storage," International Journal of Automation and Computing, Vol. 12, No. 1, pp. 43-49, 2015.

5. Zhang, R., Xu, Y., Harrison, D., Fyson, J., Southee, D., and Tanwilaisiri, A., "Fabrication and Characterisation of Energy Storage Fibres," Proc. of 20th International Conference on Automation and Computing (ICAC), pp. 228-230, 2014.

6. Zhao, S., Wu, F., Yang, L., Gao, L., and Burke, A. F., "A Measurement Method for Determination of DC Internal Resistance of Batteries and Supercapacitors," Electrochemistry Communications, Vol. 12, No. 2, pp. 242-245, 2010.

7. Tsay, K.-C., Zhang, L., and Zhang, J., "Effects of Electrode Layer Composition/Thickness and Electrolyte Concentration on Both Specific Capacitance and Energy Density of Supercapacitor," Electrochimica Acta, Vol. 60, pp. 428-436, 2012.

8. Kumagai, S., Mukaiyachi, K., and Tashima, D., "Rate and Cycle Performances of Supercapacitors with Different Electrode Thickness Using Non-Aqueous Electrolyte,” Journal of Energy Storage, Vol. 3, pp. 10-17, 2015

9. Yoon, S., Jang, J. H., Bok, H. K., and Oh, S. M., "Complex Capacitance Analysis on Rate Capability of Electric-Double Layer Capacitor (EDLC) Electrodes of Different Thickness," Electrochimica Acta, Vol. 50, No. 11, pp. 2255-2262, 2005.

10. Portet, C., Taberna, P., Simon, P., and Laberty-Robert, C., "Modification of Al Current Collector Surface by Sol-Gel Deposit for Carbon-Carbon Supercapacitor Applications," Electrochimica Acta, Vol. 49, No. 6, pp. 905-912, 2004.

11. Bo, Z., Zhu, W., Ma, W., Wen, Z., Shuai, X., et al., "Vertically Oriented Graphene Bridging Active-Layer/Current-Collector Interface for Ultrahigh Rate Supercapacitors," Advanced Materials, Vol. 25, No. 40, pp. 5799-5806, 2013.

12. Zhou, R., Meng, C., Zhu, F., Li, Q., Liu, C., Fan, S., and Jiang, K., "High-Performance Supercapacitors Using a Nanoporous Current Collector Made from Super-Aligned Carbon Nanotubes," Nanotechnology, Vol. 21, No. 34, Paper No. 345701, 2010.

13. Dyatkin, B., Presser, V., Heon, M., Lukatskaya, M. R., Beidaghi, M., and Gogotsi, Y., "Development of a Green Supercapacitor Composed Entirely of Environmentally Friendly Materials," ChemSusChem, Vol. 6, No. 12, pp. 2269-2280, 2013.

14. Liu, J., Mirri, F., Notarianni, M., Pasquali, M., and Motta, N., "High Performance All-Carbon Thin Film Supercapacitors," Journal of Power Sources, Vol. 274, pp. 823-830, 2015.

15. Xu, Y., Tao, Y., Zheng, X., Ma, H., Luo, J., et al., "A Metal-Free Supercapacitor Electrode Material with a Record High Volumetric Capacitance over $800 \mathrm{~F} \mathrm{~cm}^{-3}$," Advanced Materials, Vol. 27, No. 48, pp. 8082-8087, 2015.

16. Blomquist, N., Wells, T., Andres, B., Bäckström, J., Forsberg, S., and Olin, H., "Metal-Free Supercapacitor with Aqueous Electrolyte and Low-Cost Carbon Materials," Scientific Reports, Vol. 7, Article No. 39836, 2017.

17. Espalin, D., Muse, D. W., MacDonald, E., and Wicker, R. B., "3D Printing Multifunctionality: Structures with Electronics," The International Journal of Advanced Manufacturing Technology, Vol. 72, Nos. 5-8, pp. 963-978, 2014.

18. Vatani, M., Lu, Y., Engeberg, E. D., and Choi, J.-W., “Combined 3D Printing Technologies and Material for Fabrication of Tactile Sensors," International Journal of Precision Engineering and Manufacturing, Vol. 16, No. 7, pp. 1375-1383, 2015.

19. Kim, M.-S., Chu, W.-S., Kim, Y.-M., Avila, A. P. G., and Ahn, S.-H., "Direct Metal Printing of 3D Electrical Circuit Using Rapid Prototyping," International Journal of Precision Engineering and Manufacturing, Vol. 10, No. 5, pp. 147-150, 2009.

20. Sun, K., Wei, T. S., Ahn, B. Y., Seo, J. Y., Dillon, S. J., and Lewis, J. A., "3D Printing of Interdigitated Li-Ion Microbattery Architectures," Advanced Materials, Vol. 25, No. 33, pp. 4539-4543, 2013.

21. Zhao, C., Wang, C., Gorkin Iii, R., Beirne, S., Shu, K., and Wallace, G. G., "Three Dimensional (3D) Printed Electrodes for Interdigitated Supercapacitors," Electrochemistry Communications, Vol. 41, pp. 2023, 2014.

22. Xinhua, L., Shengpeng, L., Zhou, L., Xianhua, Z., Xiaohu, C., and Zhongbin, W., "An Investigation on Distortion of PLA Thin-Plate Part in the FDM Process," The International Journal of Advanced Manufacturing Technology, Vol. 79, Nos. 5-8, pp. 1117-1126, 2015.

23. Gibson, I., Rosen, D., and Stucker, B., Additive Manufacturing Technologies: 3D Printing," Rapid Prototyping and Direct Digital Manufacturing, 2015.

24. Anitha, R., Arunachalam, S., and Radhakrishnan, P., "Critical Parameters Influencing the Quality of Prototypes in Fused Deposition Modelling," Journal of Materials Processing Technology, Vol. 118, Nos. 1-3, pp. 385-388, 2001.

25. Choi, J.-W., Medina, F., Kim, C., Espalin, D., Rodriguez, D., et al., "Development of a Mobile Fused Deposition Modeling System with Enhanced Manufacturing Flexibility,” Journal of Materials Processing Technology, Vol. 211, No. 3, pp. 424-432, 2011. 
26. Pandey, P., Reddy, N. V., and Dhande, S., "Real Time Adaptive Slicing for Fused Deposition Modelling," International Journal of Machine Tools and Manufacture, Vol. 43, No. 1, pp. 61-71, 2003.

27. Tian, X., Jin, J., Yuan, S., Chua, C. K., Tor, S. B., and Zhou, K., "Emerging 3D-Printed Electrochemical Energy Storage Devices: A Critical Review," Advanced Energy Materials, 2017. (DOI: 10.1002/ aenm.201700127)

28. Zhakeyev, A., Wang, P., Zhang, L., Shu, W., Wang, H., and Xuan, J., "Additive Manufacturing: Unlocking the Evolution of Energy Materials,” Advanced Science, 2017. (DOI: 10.1002/advs.201700187)

29. Zhang, F., Wei, M., Viswanathan, V. V., Swart, B., Shao, Y., Wu, G., and Zhou, C., "3D Printing Technologies for Electrochemical Energy Storage,” Nano Energy, Vol. 40, pp. 418-431, 2017.

30. Zhu, C., Liu, T., Qian, F., Chen, W., Chandrasekaran, S., et al., "3D Printed Functional Nanomaterials for Electrochemical Energy Storage," Nano Today, Vol. 15, pp. 107-120, 2017.

31. Wang, G., Zhang, L., and Zhang, J., "A Review of Electrode Materials for Electrochemical Supercapacitors," Chemical Society Reviews, Vol. 41, No. 2, pp. 797-828, 2012. 